\title{
Lower Sedentary Metabolic Rate in Women Compared with Men
}

\author{
Robert Ferraro, Stephen Lillioja, Anne-Marie Fontvieille, Russell Rising, Clifton Bogardus, and Eric Ravussin \\ Clinical Diabetes and Nutrition Section, National Institute of Diabetes and Digestive and Kidney Diseases, \\ National Institutes of Health, Phoenix, Arizona 85016
}

\begin{abstract}
Since females have a greater prevalence of obesity compared with males, the question arises whether females have lower metabolic rate than males after adjusting for differences in body weight and composition. 24-h energy expenditure (24EE), basal metabolic rate (BMR), and sleeping metabolic rate (SMR) were measured in a respiratory chamber in 235 healthy, nondiabetic Caucasian subjects (114 males, 121 females). Body composition was determined by hydrodensitometry. 24EE was $124 \pm 38 \mathrm{kcal} / \mathrm{d}(P<0.002)$ higher in males than females after adjusting for differences in fat-free mass, fat mass, and age. Spontaneous physical activity was not significantly different between males and females. Since adjusted 24EE was $106 \pm 39 \mathrm{kcal} / \mathrm{d}(P<0.01)$ higher in females during the luteal phase of the menstrual cycle compared with females during the follicular phase, energy expenditure was analyzed in a subset ( $>50 \mathrm{yr}$ ) to minimize the confounding effect of menstrual status. 24EE (160 $\pm 66 \mathrm{kcal} / \mathrm{d} ; P<0.03)$, BMR $(116 \pm 45 ; P<0.02)$, and SMR $(208 \pm 68 \mathrm{kcal} / \mathrm{d} ; P<0.005)$ were higher in males compared with females of the older subset after adjusting for differences in body composition, age, and activity. In summary, sedentary $24 \mathrm{EE}$ is $\sim 5-10 \%$ lower in females compared with males after adjusting for differences in body composition, age, and activity. (J. Clin. Invest. 1992. 90:780-784.) Key words: 24-hour energy expenditure $\bullet$ indirect calorimetry • sex
\end{abstract}

\section{Introduction}

Obesity is common in the United States and is a major public health problem because of its association with considerable morbidity, including hypertension, diabetes mellitus, and coronary artery disease $(1,2)$. Obesity develops as a consequence of long-term positive energy balance reflecting an imbalance between energy intake and energy expenditure. Rates of energy expenditure show strong familial aggregation and a low metabolic rate for a given body size and body composition is a risk factor for body weight gain (3). Since females have a greater prevalence of obesity compared with males (1), the question arises whether females have lower metabolic rates than males.

On the basis of body size alone, males have higher metabolic rates than females. However, when basal metabolic rate

Address correspondence to Eric Ravussin, National Institutes of Health, 4212 N. 16th Street, Room 541, Phoenix, AZ 85016.

Dr. Ferraro's current address is Southern Illinois University, School of Medicine, Department of Medicine, P.O. Box 19230, Springfield, IL 62794.

Received for publication 16 July 1991 and in revised form 10 February 1992.

1. Abbreviations used in this paper: BMR, basal metabolic rate; FFM, fat-free mass; FM, fat mass; SMR, sleeping metabolic rate; SPA, spontaneous physical activity; 24EE, 24-h energy expenditure.

The Journal of Clinical Investigation, Inc.

Volume 90, September 1992, 780-784
(BMR) ${ }^{1}$ is adjusted for individual differences in fat-free mass (FFM), males and females are found to have similar metabolic rates (4). Several recent cross-sectional studies have confirmed this finding $(5,6)$.

Of the three major components constituting total daily energy expenditure, BMR accounts for $60-70 \%$. Interest in the measurement of total daily energy expenditure has spawned the construction of human respiratory chambers in Europe (7$10)$, the United States $(11,12)$, and Africa (13) over the past $10 \mathrm{yr}$. Studies have been limited to small numbers of subjects, often involving a single sex. In one of first comparative studies of 24-h metabolic rate between seven males and eight females, Webb (14) reported that 24-h energy expenditure (24EE) was highly correlated with fat-free body mass and was not affected by age or sex. Ravussin et al. (11) confirmed that FFM was the best determinant of 24EE in a multiracial population. Sex and age were not found to have a significant effect on the relationship. In this study, 27 subjects, including 15 females, had noninsulin dependent diabetes mellitus, a condition in which metabolic rate is increased (15); therefore, diabetic status may have been a confounding factor leading the authors to conclude that sex did not have an impact on energy expenditure.

The present study was conducted to investigate the role of sex as a possible determinant of $24 \mathrm{EE}$ and its components independent of body size and composition in a population of healthy Caucasian males and females covering a wide range of body size, body composition, and age.

\section{Methods}

Subjects. From May 1985 through August 1990, 235 Caucasian subjects ( 114 males, 121 females) were admitted to the Clinical Diabetes and Nutrition Section of the National Institute of Diabetes, Digestive, and Kidney Diseases in Phoenix for research protocols including measurements of 24EE and body composition under standardized conditions. Their characteristics are given in Table I. Written informed consent was obtained from all subjects. Only healthy subjects, determined by history, physical examinations, and laboratory analyses of serum electrolytes, blood urea nitrogen, creatinine, liver function tests, thyroid function tests ( $\mathrm{TSH}$, total $\mathrm{T}_{4}$, and $\mathrm{T}_{3} \mathrm{RU}$ ), complete blood count, urinalysis, and without history of eating disorders were included in this analysis. None of the females were pregnant. Upon admission all subjects received a weight maintenance diet consisting of 50\% carbohydrate, $30 \%$ fat, and $20 \%$ protein. A $75-\mathrm{g}$ oral glucose-tolerance test was aḍministered, after $\geq 2 \mathrm{~d}$ on the diet, to all subjects except 23 endurance athletes with a negative family history for diabetes mellitus. None of the subjects had diabetes mellitus according to the World Health Organization criteria (16), 15 subjects were glucose intolerant ( 3 males, 12 females). None of the subjects was taking medications, including oral contraceptives, during the admission to the metabolic ward. Body composition was estimated by hydrodensitometry with simultaneous determination of lung residual volume and percent body fat calculated from body density using the Siri equation $(17,18)$.

$24 E E$. $24 \mathrm{EE}$ was measured in the respiratory chamber as previously described (11). Spontaneous physical activity (SPA) was measured continuously by two microwave radars. Vigorous physical activity was not allowed during chamber measurements. SPA was reported as the percent of time during which a subject was moving in the chamber. 
Table I. Physical Characteristics of the Subjects

\begin{tabular}{lccc}
\hline & $\begin{array}{c}\text { Males } \\
(n=114)\end{array}$ & $P^{*}$ & $\begin{array}{c}\text { Females } \\
(n=121)\end{array}$ \\
\hline Weight $(\mathrm{kg})$ & $84.1 \pm 23.6(51-150)$ & NS & $80.9 \pm 22.8(41-138)$ \\
Age $(\mathrm{yr})$ & $34 \pm 14(19-81)$ & NS & $38 \pm 17(18-85)$ \\
Height $(\mathrm{cm})$ & $176 \pm 7(155-194)$ & $<0.01$ & $163 \pm 7(147-183)$ \\
Body fat $(\%)$ & $22 \pm 12(3-48)$ & $<0.01$ & $39 \pm 11(11-56)$ \\
Fat-free mass (kg) & $63.2 \pm 10.3(41-93)$ & $<0.01$ & $47.6 \pm 8.9(31-71)$ \\
Fat mass $(\mathrm{kg})$ & $20.8 \pm 16.5(2-70)$ & $<0.01$ & $33.3 \pm 16.2(5-74)$
\end{tabular}

Values are mean $\pm \mathrm{SD}$; range in parentheses. * For comparison between sexes.

The subjects entered the respiratory chamber at 0745 after $6 \pm 5 \mathrm{~d}$ (range: 2-45) of receiving the standardized weight maintenance diet, and remained inside until 0700 the next day. 24EE was derived from the continuous 23-h measurement extrapolated to $24 \mathrm{~h}$. Meals, supplied from the metabolic kitchen, were $\sim 80 \%$ of the caloric prescription on the ward to account for the decrease in physical activity in the chamber.

Sleeping metabolic rate (SMR) was the metabolic rate measured between 2300 and 0500 hours when the 15 -min activity by radar is $<1.5 \%$. BMR was measured using a ventilated plastic hood placed over the subject's head at 0700,11 hours after the evening snack. After a 20-25-min adaptation period, BMR was measured for 9-15 min with the subject motionless and awake.

Menstrual cycle phase. The medical charts of all females in this analysis were reviewed for regularity of menses, date of initiation of the last menstrual period, and documentation of menopausal status. The menstrual status was estimated by calculating the time elapsed between the measurement in the respiratory chamber from the last menses. The assignment of menstrual cycle phase was based on the following definitions: follicular phase, if $<12 \mathrm{~d}$ since last menstruation and luteal phase if $>18 \mathrm{~d}$ since last menstruation. By the chart review procedure, menstrual phase could be ascertained in 42 females ( 30 follicular, 12 luteal). Postmenopausal status $(n=28)$ was assigned on the basis of age ( $>50 \mathrm{y}$ ) or surgical history. Postmenopausal females and females in the follicular phase were combined to form a "nonluteal" group ( $n$ $=58$ ). The physical characteristics of the luteal and nonluteal groups are presented in Table II.

Table II. Physical Characteristics in a Subset of Female Subjects with Known Menstrual Status (Luteal vs. Nonluteal*)

\begin{tabular}{lccc}
\hline & $\begin{array}{c}\text { Luteal } \\
(n=12)\end{array}$ & $P^{\ddagger}$ & $\begin{array}{c}\text { Nonluteal } \\
(n=58)\end{array}$ \\
\hline Weight $(\mathrm{kg})$ & $84.6 \pm 20.5$ & NS & $75.2 \pm 17.0$ \\
Age $(\mathrm{yr})$ & $26 \pm 5$ & $<0.01$ & $49 \pm 18$ \\
Height $(\mathrm{cm})$ & $164 \pm 6$ & NS & $162 \pm 7$ \\
Body fat $(\%)$ & $38 \pm 11$ & NS & $41 \pm 9$ \\
Fat-free mass (kg) & $50.8 \pm 6.8$ & $<0.01$ & $43.8 \pm 7.8$ \\
Fat mass (kg) & $33.7 \pm 15.8$ & NS & $31.4 \pm 11.8$
\end{tabular}

Values are mean \pm SD. ${ }^{*}$ No differences in $24 \mathrm{EE}, \mathrm{BMR}$, and SMR were found between postmenopausal females $(n=28)$ and females during the follicular phase of the mentrual cycle $(n=30)$ after adjusting for body composition, age, and activity. Both groups were combined to form a nonluteal group for comparison with females during the luteal phase of the menstrual cycle (see Results). ${ }^{\ddagger}$ For comparison between groups.
Subjects older than $50 \mathrm{yr}$. To minimize the potential confounding effects of menstrual cycle phase, a subset of subjects older than $50 \mathrm{yr}(n$ $=36$; males $=12$, females $=24$ ) was used to evaluate the role of sex as a determinant of energy expenditure. Physical characteristics are presented on Table III.

Statistical analyses. Statistical analyses were performed with the procedures of the SAS Institute (Cary, NC). The distributions of some of the variables within each group were not uniform, therefore, a nonparametric test (Wilcoxon rank sum) was used to test for differences between groups. Correlations are Pearson product-moment correlations. The significance level was 0.05 .

The effect of sex on energy expenditure was assessed by analysis of covariance using the general linear model procedures. This approach was employed rather than normalizing the data for comparison by dividing by FFM to avoid the introduction of a mathematical bias, since the $x$ - and $y$-intercepts of the relationship between energy expenditure and FFM are significantly different than zero (19). After establishing parallelism of the regression lines by testing homogeneity of slopes, sex (a two-level discrete variable) was added to multiple linear regression models after FFM, fat mass (FM), age, and SPA. Sex was either $(a)$ a significant determinant of metabolic rate, in which case a sex (males) had higher (positive coefficients) or lower metabolic rate (negative coefficients) with reference to the opposite sex (females) after normalizing for the above four covariates or $(b)$ was not a significant determinant. The residuals for each of the models reported had a normal distribution.

The effect of menstrual cycle phase as an independent determinant of energy expenditure in females was assessed in an analogous manner with menstrual cycle phase as the discrete variable.

\section{Results}

All subjects. The results of energy expenditure are summarized for the two groups in Table IV. The relationship of 24EE and FFM is depicted in Fig. 1. FFM, alone, explained $69 \%$ of the variance of $24 \mathrm{EE}$ ( $\mathrm{kcal} / \mathrm{d}=665+26.1 \times \mathrm{FFM} ; r^{2}=0.69, P$ $<0.0001)$. Sex was a significant determinant of 24EE when tested in the simple relationship between 24EE and FFM ( $P$ $<0.0001)$ and, in this model, 24EE was $149 \pm 35 \mathrm{kcal} / \mathrm{d}$ lower in males compared with females. FM was also a significant determinant of $24 \mathrm{EE}$, explaining an additional $12 \%$ of variance and accounted for $9.1 \mathrm{kcal} \cdot \mathrm{d}^{-1} \cdot \mathrm{kg}$ of body fat ${ }^{-1}$. In the relationship between 24EE and FFM, FM, and age, 24EE was $124 \pm 38 \mathrm{kcal} / \mathrm{d}(P<0.002)$ higher in males than females and $97 \pm 34 \mathrm{kcal} / \mathrm{d}(P<0.01)$ after adjusting for differences in SPA (Table V, Fig. 2).

The regression equations for BMR and SMR with the covariates FFM, FM, age, and sex are presented in Table V. Although males tended to have higher adjusted BMR and SMR,

Table III. Physical Characteristics in a Subset of Subjects $50 \mathrm{yr}$ or Older

\begin{tabular}{lccc}
\hline & $\begin{array}{c}\text { Males } \\
(n=12)\end{array}$ & $P^{*}$ & $\begin{array}{c}\text { Females } \\
(n=24)\end{array}$ \\
\hline Weight (kg) & $74.6 \pm 11.3$ & NS & $70.5 \pm 18.0$ \\
Age (yr) & $69 \pm 7$ & NS & $66 \pm 9$ \\
Height (cm) & $173 \pm 8$ & $<0.01$ & $161 \pm 7$ \\
Body fat (\%) & $28 \pm 8$ & $<0.01$ & $42 \pm 6$ \\
Fat-free mass (kg) & $53.0 \pm 7.8$ & $<0.01$ & $40.4 \pm 9.0$ \\
Fat mass (kg) & $21.7 \pm 8.4$ & $<0.05$ & $30.2 \pm 10.2$
\end{tabular}

Values are mean $\pm \mathrm{SD}$. * For comparison between sexes. 
Table IV. Results of Energy Expenditure and Its Components

\begin{tabular}{cccc}
\hline & $\begin{array}{c}\text { Males } \\
(n=114)\end{array}$ & $P$ & $\begin{array}{c}\text { Females } \\
(n=121)\end{array}$ \\
\hline $\begin{array}{c}\text { 24-h energy expenditure } \\
\text { (kcal/d) }\end{array}$ & $2,266 \pm 357$ & $<0.01$ & $1,950 \pm 352$ \\
Basal metabolic rate & $(1,584-3,263)$ & & $(1,362-2,973)$ \\
$\quad(k c a l / d)$ & $1,785 \pm 352$ & $<0.01$ & $1,534 \pm 314$ \\
Sleeping metabolic rate & $(1,257-2,765)$ & & $(1,038-2,435)$ \\
$\quad(k c a l / d)$ & $1,630 \pm 260$ & $<0.01$ & $1,418 \pm 250$ \\
Spontaneous physical & $(1,166-2,510)$ & & $(958-2,138)$ \\
activity (\%) & $8.4 \pm 3.2$ & NS & $8.2 \pm 3.1$ \\
& $(3.1-20.4)$ & & $(2.7-19.3)$
\end{tabular}

Values are mean $\pm \mathrm{SD}$, range in parentheses. * For comparison between sexes.

sex was not a significant determinant of BMR $(P=0.4)$ or SMR $(P=0.06)$.

Group with known menstrual status. The role of menstrual cycle phase as a determinant of energy expenditure was evaluated in females by multiple linear regression analyses. No significant differences in energy expenditure, adjusted for body composition, age, and SPA, were found between postmenopausal females and females during the follicular phase of the menstrual cycle. After combining these two groups $(n=58)$ to form a nonluteal group, comparison with the group of females during the luteal phase of the menstrual cycle $(n=12)$ was performed. 24EE $(106 \pm 39 \mathrm{kcal} / \mathrm{d} ; P<0.01)$, BMR $(199 \pm 53 ; P$ $<0.001)$, and SMR (108 $\pm 42 \mathrm{kcal} / \mathrm{d} ; P<0.02$ ), adjusted for differences in FFM, FM, age, and SPA, were higher in females during the luteal phase.

Group older than $50 \mathrm{yr}$. To evaluate the role of sex on metabolic rate without the confounding effects of menstrual status, multiple linear regression analyses were performed on a subset composed of 12 males and 24 females, older than $50 \mathrm{yr}$. 24EE, adjusted for differences in FFM, FM, age, and SPA, was

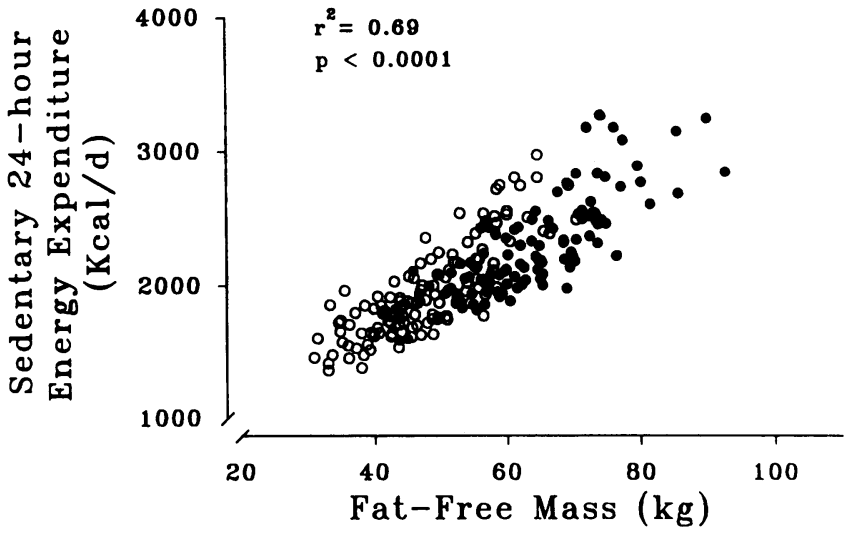

Figure 1. The relationship between 24-h sedentary energy expenditure $(\mathrm{kcal} / \mathrm{d})$ and fat-free mass $(\mathrm{kg})$ in 235 Caucasian subjects. Males $(n$ $=114)$ are represented by closed circles $(\bullet)$ and females $(n=121)$ are represented by open circles $(0)$.

$160 \pm 66 \mathrm{kcal} / \mathrm{d}(P<0.03)$ higher in males than females (Fig. $2)$. BMR and SMR, adjusted for body composition and age, were $116 \pm 45 \mathrm{kcal} / \mathrm{d}(P<0.02)$ and $208 \pm 68 \mathrm{kcal} / \mathrm{d}(P$ $<0.005$ ) higher in males than females, respectively.

\section{Discussion}

Sedentary 24EE adjusted for differences in body composition, age, and activity were higher in males $(\approx 100 \mathrm{kcal} / \mathrm{d})$ than in females in a cross-sectional analysis of data obtained in 235 healthy Caucasians. Adjusted BMR and SMR, however, were similar, although with a tendency toward higher values in males. Since spontaneous physical activity was not signifcantly different between either group, none of the components of energy expenditure measured in our chamber could account for the difference.

Table V. Regression Equations* for Sedentary 24-hr Energy Expenditure, Basal Metabolic Rate, and Sleeping Metabolic Rate with the Covariates FFM, FM, Age, SPA, ${ }^{\neq}$and Sex

\begin{tabular}{|c|c|c|c|c|c|c|}
\hline Intercept & FFM & FM & AGE & SPA & $\operatorname{Sex}^{\S}$ & $r^{2}$ \\
\hline & $k g$ & $k g$ & $y r$ & $\%$ & & \\
\hline \multicolumn{7}{|l|}{ Sedentary $24 \mathrm{EE}^{\|}$} \\
\hline $\begin{array}{c}553 \pm 79 \\
(P<0.0001)\end{array}$ & $\begin{array}{c}20.4 \pm 1.4 \\
(P<0.0001)\end{array}$ & $\begin{array}{c}8.8 \pm 0.8 \\
(P<0.0001)\end{array}$ & $\begin{array}{l}-1.5 \pm 0.7 \\
(P<0.05)\end{array}$ & $\begin{array}{c}+23.3 \pm 3.2 \\
(P<0.0001)\end{array}$ & $\begin{array}{c}+97 \pm 34 \\
(P<0.01)\end{array}$ & 0.853 \\
\hline $\begin{array}{c}757 \pm 82 \\
(P<0.0001)\end{array}$ & $\begin{array}{c}19.6 \pm 1.6 \\
(P<0.0001)\end{array}$ & $\begin{array}{c}9.6 \pm 0.8 \\
(P<0.0001)\end{array}$ & $\begin{array}{c}-1.6 \pm 0.8 \\
(P<0.05)\end{array}$ & & $\begin{array}{c}+124 \pm 38 \\
(P<0.002)\end{array}$ & 0.819 \\
\hline \multicolumn{7}{|l|}{ BMR } \\
\hline $\begin{array}{c}710 \pm 106 \\
(P<0.0001)\end{array}$ & $\begin{array}{c}17.2 \pm 2.0 \\
(P<0.0001)\end{array}$ & $\begin{array}{c}5.3 \pm 1.1 \\
(P<0.0001)\end{array}$ & $\begin{array}{c}-4.5 \pm 1.0 \\
(P<0.0001)\end{array}$ & & $\begin{array}{c}+44 \pm 49 \\
(\mathrm{NS})\end{array}$ & 0.639 \\
\hline \multicolumn{7}{|l|}{ SMR } \\
\hline $\begin{array}{c}551 \pm 63 \\
(P<0.0001)\end{array}$ & $\begin{array}{c}14.8 \pm 1.2 \\
(P<0.0001)\end{array}$ & $\begin{array}{c}6.2 \pm 0.7 \\
(P<0.0001)\end{array}$ & $\begin{array}{c}-1.1 \pm 0.6 \\
(\mathrm{NS})\end{array}$ & & $\begin{array}{c}+54 \pm 29 \\
(\mathrm{NS})\end{array}$ & 0.786 \\
\hline
\end{tabular}

$n=235 .^{*}$ The value reported for each term is the parameter estimate \pm SE. Significance levels are reported in parentheses beneath each term. ‡ SPA, spontaneous physical activity. ${ }^{\S}$ The values for sex (a two-level discrete variable) represent the differences in energy expenditure between males and females after adjustment for the covariates in the respective models. Positive values signify that males have higher adjusted energy expenditure than females (see Methods). "The multiple linear regression analysis of 24EE is performed with and without the variable SPA. 


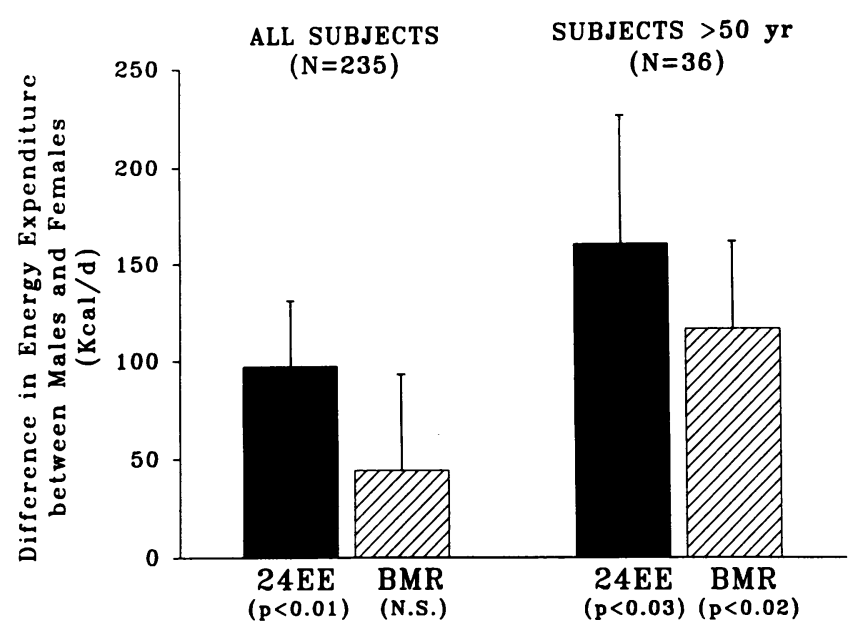

Figure 2. The effect of sex in the entire group of 235 Caucasian subjects and in a subset of subjects older than 50 yr was estimated by using a two-level class variable (sex) in multiple linear regression analyses of 24-h energy expenditure (24EE) (solid bar) and basal metabolic rate $(B M R)$ (hatched bar) after normalizing for differences in fat-free mass, fat mass, age, and spontaneous physical activity (see Methods). Each bar represents the coefficient for the parameter $(\operatorname{sex}) \pm$ the SE of the estimate. Males had higher adjusted energy expenditure compared with females by the values presented in the figure. The significance levels for sex, in the respective multiple linear regression models, are given in parentheses.

Menstrual function was not controlled for in this study. The cyclic nature of progesterone secretion in females is thought to mediate changes in metabolic rate. 24EE has been reported to be $9 \%$ higher in females during the luteal phase of the ovulatory cycle (20). Variability of SMR as a function of ovulatory phase has also been reported (21). Since most of the females in this study were premenopausal, it could be argued that the sex difference in energy expenditure would be attenuated by those females in the luteal phase of the menstrual cycle and that adjustment for ovulatory phase would reveal an even greater sex effect. By medical chart review, we were able to assign menstrual cycle status in 42 females. In addition, 28 females were assigned postmenopausal status based on age criteria and by surgical history. Multiple linear regression analyses of 24EE, BMR, and SMR did not reveal significant differences between postmenopausal females and females during the follicular phase of the menstrual cycle after adjustment for body composition, age, and SPA. In contrast, adjusted 24EE, BMR, and SMR were higher in females during the luteal phase compared with the nonluteal group. These results confirm previous studies $(20,21)$ and provide evidence that postmenopausal females do not have a lower metabolic rate than females in the follicular phase of the menstrual cycle after adjustment for age and differences in body composition. However, through the loss of the postovulatory increase in metabolic rate, postmenopausal females have a reduction in annual metabolic rate of $\sim 15,000-20,000 \mathrm{kcal}$. This may explain at least partially the increase in the rate of overweight observed in females throughout the ages ( 1 ).

To minimize the potential confounding effect of the menstrual cycle on energy expenditure in females, we analyzed a subset of males and females older than $50 \mathrm{yr}$. Adjusted 24EE,
BMR, and SMR were all significantly higher in males and the differences were greater than in the younger group.

Our model of energy expenditure is based on the direct and linear relationship between metabolic rate and body size (within the range examined in this study) expressed by its two basic components, i.e., FFM and FM. FM was a significant determinant of BMR and SMR as well as 24EE. After adjusting for the above covariates, males were found to have a significantly higher metabolic rate than females and even more so at an older age. The difference in energy expenditure accounted for by sex is small, representing 5-10\% of total daily energy expenditure. Webb (14) had insufficient numbers of subjects to find a significant sex difference. A potentially confounding variable in the design of our previous study of energy expenditure was diabetic status, which may have precluded the observation of a significant effect of sex on 24EE in a multiracial cohort (11).

Although progesterone is invoked to explain intraindividual differences of metabolic rate in females, other sex hormones may be responsible for sex differences. The role of androgens as modulators of energy balance has been extensively investigated in animals (22-24). Basal energy expenditure has been reported $18 \%$ higher in postpubertal bulls (25) and 13$27 \%$ higher in rams compared with their castrated male counterparts (26).

Several lines of investigation in humans also suggest that androgens have thermogenic properties. In maturing boys and girls aged 8-18 yr, a close correlation was demonstrated in males $(r=0.66)$ between urinary 17-ketosteroid excretion with basal oxygen consumption adjusted for body composition, but not in females (27). The putative agent responsible for the qualitative differences in urinary ketosteroid excretion and metabolic rate was suggested to be testosterone. Additional indirect evidence for the thermogenic nature of testosterone comes from two recent reports. In the first study, free testosterone levels were found to be higher in women with an android pattern of fat distribution compared with women with gynoid distribution (28). Also, Bruemann et al. (29), using whole body direct calorimetry, reported that 24EE adjusted for FFM, FM, and age was higher in obese women with an android fat distribution compared with those with a gynoid distribution.

Sex-specific muscle fiber composition $(30,31)$ could play a role in determining resting muscle metabolism and, hence, metabolic rate, since resting muscle metabolism accounts for a significant part of the variability of metabolic rate (32). Also, differences in basal hepatic gluconeogenesis, $\mathrm{Na}^{+}-\mathrm{K}^{+}$ATPase activity, sympathetic nervous activity, and decreased body core temperature are other possible mechanisms to explain lower metabolic rate in females. Although this study did not focus on identifying mechanisms by which females have lower metabolic rate than males, androgen status, skeletal muscle metabolism, and sympathetic nervous system activity are potentially important candidates for future investigation.

\section{Acknowledgments}

We thank Carol Lamkin and all of the Clinical Diabetes and Nutrition Section nursing staff; Helen Seagle and the dietary staff; Tom Anderson, Inge Harper, Laurent Christin, Francesco Zurlo, Karen Larsen, and Mohammed Saad for their technical assistance; and all of the subjects who made this study possible. 


\section{References}

1. National Center for Health Statistics. 1987. Anthropometric reference data and prevalence of overweight, United States 1976-1980. National Health Survey, series 11, No. 238. DHHS publication (PHS) 87-1688. National Center for Health Statistics, Hyattsville, MD.

2. Lew, E. A., and L. Garfinkel. 1979. Variations in mortality by weight among 750,000 men and women. J. Chronic Dis. 32:563-576.

3. Ravussin, E., S. Lillioja, W. C. Knowler, L. Christin, D. Freymond, W. G. H. Abbott, V. Boyce, B. V. Howard, and C. Bogardus. 1988. Reduced rate of energy expenditure as a risk factor for body-weight gain. N. Engl. J. Med. 318:467-472.

4. Cunningham, J. J. 1980. A re-analysis of the factors influencing basal metabolic rate in normal adults. Am. J. Clin. Nutr. 33:2372-2374.

5. Owen, O. E. 1988. Resting metabolic requirements of men and women. Mayo Clin. Proc. 63(5):503-510.

6. Mifflin, M. D., S. T. St. Joer, L. A. Hill, B. J. Scott, S. A. Daughty, and Y. O. Koh. 1990. A new predictive equation for resting energy expenditure in healthy individuals. Am. J. Clin. Nutr. 51:241-247.

7. Van Es, A. J., J. E. Voghy, C. Niessen, J. Veth, I. Roderberg, V. Teeuwse, J. Dhuyvetter, P. Deurenberg, J. G. Hautvast, and E. Van ser Beek. 1984. Human energy metabolism below, near and above energy equilibrium. Br. J. Nutr. $52: 429-442$.

8. Dauncey, Y. M. J., P. R. Murgatroyd, and T. J. Cole. 1978. A human calorimeter for the direct and indirect measurement of $24 \mathrm{~h}$ energy expenditure. Br. J. Nutr. 39:557-566.

9. Dullo, A. G., M. N. Ismail, M. Ryall, G. Meals, C. A. Geissler, and D. S. Miller. 1988. A low budget easy-to-operate room respirometer for measuring daily energy expenditure in man. Am. J. Clin. Nutr. 48:1267-1274.

10. Jequier, E., and Y. Schutz. 1983. Long-term measurements of energy expenditure in humans using a respiration chamber. Am. J. Clin. Nutr. 38:989998.

11. Ravussin, E., S. Lillioja, T. E. Anderson, L. Christin, and C. Bogardus. 1986. Determinants of 24-hour energy expenditure in man. J. Clin. Invest. 79:1568-1578.

12. Rumpler, W. V., J. L. Seale, J. M. Conway, and P. W. Moe. 1990. Repeatability of 24-h energy expenditure in humans by indirect calorimetry. Am. J. Clin. Nutr. 51:147-152.

13. Minghelli, G., Y. Schutz, A. Charbonnier, R. Whitehead, and E. Jequier. 1990. Twenty-four hour energy expenditure and basal metabolic rate measured in a whole-body indirect calorimeter in Gambian men. Am. J. Clin. Nutr. 51:563-570.

14. Webb, P. 1981. Energy expenditure and fat-free mass in men and women. Am. J. Clin. Nutr. 34:1816-1826.

15. Bogardus, C., M. R. Taskinen, J. Zawadzki, S. Lillioja, D. Mott, and B. V. Howard. 1986. Increased resting metabolic rates in obese subjects with non-insulin dependent diabetes mellitus and the effect of sulfonlyurea therapy. Diabetes. $35: 1-5$
16. World Health Organization. 1985. WHO Technical Report Series No. 727. Diabetes Mellitus. World Health Organization, Geneva.

17. Goldman, R. F., and E. R. Buskirk. 1961. A method for underwater weighing and the determination of body density. In Techniques for Measuring Body Composition. J. Brozek and A. Herschel, editors. National Academy of Sciences, National Research Council, Washington, DC. 78-106.

18. Siri, W. E. 1961. Body composition from fluid and density: analysis of methods. In Techniques for Measuring Body Composition. J. Brozek and A. Herschel, editors. National Academy of Sciences, National Research Council, Washington, DC. 233-244.

19. Ravussin, E., and C. Bogardus. 1989. Relationship of genetics, age and physical fitness to daily energy expenditure and fuel utilization. Am. J. Clin. Nutr. 49:968-975.

20. Webb, P. 1986. 24-hour energy expenditure and the menstrual cycle. $A m$. J. Clin. Nutr. 44:614-619.

21. Bisdee, J. T., W. P. T. James, and M. A. Shaw. 1989. Changes in energy expenditure during the menstrual cycle. Br. J. Nutr. 61(2):187-199.

22. Mitchell, J. S., and R. E. Keesey. 1974. The effects of lateral hypothalamic lesions and castration upon the body weight and composition of male rats. Behav. Biol. 11:69-82.

23. Lobley, G. E., A. Connell, V. Buchan, P. A. Skene, and J. M. Fletcher. 1987. Administration of testosterone to wether lambs: effects on protein and energy metabolism and growth hormone status. J. Endocrinol. 115:439-445.

24. Kemnitz, J. W., K. K. Sladky, T. J. Flitsch, S. M. Pomerantz, and R. W. Goy. 1988. Androgenic influences on body size and composition in rhesus monkeys. Am. J. Physiol. 255:E857-E864.

25. Webster, A. J. F., J. S. Smith, and G. S. Mollison. 1977. Prediction of the energy requirements for growth in beef cattle. Anim. Prod. 24:237-244.

26. Graham, N. 1967. The metabolic rate of fasting sheep in relation to total and lean body weight, and the estimation of maintenance requirements. Austr. J. Agric. Res. 18:127-136.

27. Clark, L. C., and S. M. Garn. 1954. Relationship between ketosteroid excretion and basal oxygen consumption. J. Appl. Physiol. 6:546-550.

28. Kirchner, M. A., M. D. Samojilik, E. Szmal, G. Schneider, and N. Ertel. 1990. Androgen-estrogen metabolism in women with upper body versus lower body obesity. J. Clin. Endocrinol. Metab. 70:473-479.

29. Bruemann, B., A. Astrup, N. J. Christensen, O. J. Vistor, G. Thorbek, B. Isaksson, and F. Quaade. 1983. Relation between fat distribution and energy and energy expenditure in obese women. Int. J. Obesity. 52A. (Abstr.)

30. Simoneau, J. A., and C. Bouchard. 1989. Human variation in skeletal muscle fiber-type proportion and enzyme activities. Am. J. Physiol. 257:E567E572.

31. Simoneau, J. A., G. Lortie, M. R. Boulay, M. C. Thibault, G. Theriault, and C. Bouchard. 1985. Skeletal muscle histochemical and biochemical characteristics in sedentary male and female subjects. Can. J. Physiol. Pharmacol. 63:30-35.

32. Zurlo, F., K. Larson, C. Bogardus, and E. Ravussin. 1990. Skeletal muscle metabolism is a major determinant of resting energy expenditure. J. Clin. Invest 86:1423-1427. 